\title{
Chlorophyll derivatives as visual pigments for super vision in the red
}

\author{
Ilyas Washington, ${ }^{* a}$ Jilin Zhou, ${ }^{b}$ Steffen Jockusch, ${ }^{a}$ Nicholas J. Turro, ${ }^{a}$ Koji Nakanishi ${ }^{a}$ and Janet R. Sparrow ${ }^{b}$ \\ Received 12th December 2006, Accepted 11th April 2007 \\ First published as an Advance Article on the web 1st May 2007 \\ DOI: 10.1039/b618104j
}

The primary event in vision is light-initiated activation of visual pigments. All visual pigments consist of the protein opsin bound to 11-cis-retinal and are responsible for initiating the transformation of light into an electrical signal. In a mouse model, we show that derivatives of chlorophyll can act as visual pigments initiating the transformation of light into an electrical signal and thus change the primary event in vision to initial activation of a chlorophyll derivative. Electroretinographic b-wave amplitudes recorded in response to red and blue light were two-fold greater in mice administered chlorin $e_{6}$, which accumulated in photoreceptor outer segments.

\section{Introduction}

The primary event in vision is light initiated activation of visual pigments. All visual pigments consist of the protein opsin bound to 11-cis-retinal and are responsible for initiating the transformation of light into an electrical signal, which travels down the optic nerve to the brain. In humans three visual pigments, used primarily for daytime color (photopic) vision, reside in cone cells and sense blue $(450 \mathrm{~nm})$, green $(530 \mathrm{~nm})$ and red $(560 \mathrm{~nm})$ light. One visual pigment is found in rod cells whose use is relegated to night-time (scotopic) vision and responds primarily to green $(500 \mathrm{~nm})$ light. $^{1}$ As a result of less light scattering, dim light vision in the red region of the spectra would impart a large biological advantage, especially in conditions such as of haze, fog and underwater, ${ }^{2}$ with a strong Rayleigh type $1 / \lambda^{-4}$ dependence. ${ }^{3}$ Scattering of light at $400 \mathrm{~nm}$ is 9.4 times greater than at $700 \mathrm{~nm}$ for equal incident intensity. However, as the absorption by rhodopsin, the opsinretinal complex responsible for night vision in most mammals, is minute above $600 \mathrm{~nm}$, the pigment is not believed to sense red light. Red light vision is thus limited to red cones. Red cones, however, are about 100 times less sensitive than rhodopsin in detecting light due to their relative rarity, higher rate of thermal isomerization ${ }^{4}$ and the higher reversibility of the red pigment complex $v s$. apoprotein and 11-cis-retinal, ${ }^{5}$ making them inefficient in nightvision. How might one enhance red light night-time vision?

In the compound eye of the fly (Musca, Calliphora, Drosophila) high UV sensitivity arises from the photostable pigment 3hydroxyretinol that acts as a sensitizer for rhodopsin. According to this model the photostable UV-absorbing pigment absorbs light quanta and transfers the energy to the blue-absorbing visual pigment. ${ }^{6}$ Similar energy transfer has been observed between retinol and rhodopsin in Simuliid males flies. ${ }^{7}$ Energy transfer from the carotenoid salinixanthin to bacteriorhodopsin has been observed in the eubacterium Salinibacter ruber. ${ }^{8}$

Based on the observations that a photostable derivative of chlorophyll is isolated with the rhodopsin of the deep-sea dragonfish (Stomiidae) and that this visual pigment is bleached with

${ }^{a}$ Columbia University, Department of Chemistry, NY, New York, 10027. E-mail:iw2101@columbia.edu

${ }^{b}$ Columbia University, Department of Ophthalmology, College of Physicians and Surgeons, $N Y$, New York, 10028 long wavelength light absorbed primarily by the photostable chlorophyll derivative, it has been suggested that the fish has evolved to use the chlorophyll derivative as a sensitizer to see red light. ${ }^{9,10}$ We have shown that in the presence of various porphyrins the bleaching of bovine rhodopsin in response to red light is also enhanced leading us to conclude that vision enhancement by an unbleachable chlorophyll derivative might therefore be a general phenomenon in vertebrate photoreception. ${ }^{11}$ We further showed that living rods extracted from a salamander accumulate an exogenous chlorophyll derivative that rendered them as sensitive to red light as they were to green. ${ }^{12}$ Recent observations of the Erenna siphonophore, a relative of the jellyfish, suggest red light vision may be widespread in the deep-sea ${ }^{13}$ despite the fact that no red-sensitive visual pigments have ever been isolated from deepsea fish. ${ }^{2,14-16}$ Given the above data coupled with the observations that porphyrins of virus architectures are actively transported into mammalian cells ${ }^{17}$ we hypothesized that porphyrins may be utilized to effectively enhance mammalian red light vision. In order to investigate this hypothesis, we studied whether an intravenously injected chlorophyll derivative accumulates in the eyes of mice and increases the response to red or blue light.

\section{Experimental}

\section{Animals}

BALB/C albino mice (Charles River Breeding Laboratories), which weighed 25-35 g, were used throughout these experiments. All animals were maintained on a $12 \mathrm{~h}$ light-dark schedule in a temperature and humidity-controlled environment. All protocols were approved by the Institutional Animal Care and Use Committee of Columbia University and complied with guidelines set forth by The Association for Research in Vision and Ophthalmology.

\section{Chlorin $e_{6}$ localization}

Mice $(n=4)$ were intravenously injected with $2 \mathrm{mg} \mathrm{kg}^{-1}$ of chlorin $e_{6}$ (Frontier Scientific, Logan, Utah, in a solution of phosphate buffered saline, adjusted to $\mathrm{pH} 7.4$ with $\mathrm{NaHCO}_{3}$ ). After $1 \mathrm{~h}$, the mice were sacrificed, the whole eyes were enucleated, the anterior chambers including the lenses and vitreous were removed and the remaining eyecups were homogenized in phosphate 
buffered saline ( $1 \mathrm{ml}$; $\mathrm{pH} 7.0)$. The solution was extracted with a chloroform: $\mathrm{MeOH}(3: 1)$ solution $(1 \mathrm{ml})$. The organic phase was concentrated under a stream of argon to $0.5 \mathrm{ml}$ and used directly for fluorescence spectroscopy measurements (excitation $400 \mathrm{~nm})$.

Mice $(n=3)$ were intravenously injected as described. One, two and three hours after injection the eyes along with eyes from control (non-injected) mice were dissected and the fresh retinas were prepared as whole mounts and viewed using an automated Axioplan II fluorescence microscope (Carl Zeiss, Inc.) with an AxioCam HRc digital camera and Axiovision 4.3 software (Carl Zeiss, Inc.) (fluorescence conditions: excitation $400 \mathrm{~nm}$; emission $>640 \mathrm{~nm})$.

In other experiments, whole eyes were fixed using a published procedure with slight modification. ${ }^{18}$ Briefly, eyes were removed and placed in a $25 \mathrm{ml}$ glass vial containing a $20 \mathrm{ml}$ solution of $\mathrm{NaCl}(124 \mathrm{mM}), \mathrm{KCl}(5 \mathrm{mM}), \mathrm{MgSO}_{4}(2 \mathrm{mM}), \mathrm{NaHCO}_{3}(22 \mathrm{mM})$, glucose (10 mM), $\mathrm{CaCl}_{2}(2 \mathrm{mM})$, and $\mathrm{NaH}_{2} \mathrm{PO}_{4}(1.25 \mathrm{mM})$. This mixture along with a $200 \mathrm{ml}$ water load (in a glass beaker) was placed in a domestic microwave and heated for $45 \mathrm{~s}$ at power lever 5 (temperature reached $70{ }^{\circ} \mathrm{C}$ ). The samples were allowed to cool to room temperature, rinsed once with the above solution, embedded (in OCT) and frozen with liquid nitrogen for cryostat sectioning, and subsequent fluorescence microscopy.

\section{ERG recordings}

Seven mice $(n=7)$ were used as control mice (non-injected) and ten mice $(n=10$; five of which were from the control group after recording their normal, non-injected responses), were given chlorin $e_{6}$ prior to ERG recordings. After dark-adaptation overnight, mice were intravenously injected with $2 \mathrm{mg} \mathrm{kg}^{-1}$ of chlorin $e_{6}$ (in a solution of phosphate buffered saline, adjusted to pH 7.4 with $\mathrm{NaHCO}_{3}$ ) and ERG recordings were measured 1-3 h after injection. All procedures were carried out under red safelight light (Bright Lab Jr, Delta 1/CPM, Inc., Dallas).

All ERG recordings were performed using published procedures with modification as indicated below. ${ }^{19-21}$ Pupils were dilated with phenylephrine hydrochloride $(2.5 \%)$ and cyclopentolate hydrochloride $(0.5 \%)$ applied topically to cornea. After $10 \mathrm{~min}$, mice were placed on a heating pad to maintain body temperature at $37{ }^{\circ} \mathrm{C}$ and anaesthetized with an intraperitioneal injection of a mixture of ketamine (about $80 \mathrm{mg} \mathrm{kg}^{-1}$ ) and xylazine (about $5 \mathrm{mg} \mathrm{kg} \mathrm{kg}^{-1}$ ) and corneal hydration was maintained by topical application of methyl cellulose (1 drop; 50 mg; topical to cornea, Methocel; Dow Chemical Co., Zürich, Switzerland). In addition to general anaesthesia, corneal anaesthesia was achieved with tetracaine hydrochloride $(0.5 \%$; Bausch and Lomb) and mice were situated for ERG recordings. The reference electrode (tungsten) was incorporated into an eyelid speculum and placed under the upper and lower eyelids (in contact with the sclera) of the right eye. The active electrode was a platinum-iridium wire, formed in a loop and placed on the right cornea below the pupil. Electrical contact between the cornea and electrode was achieved with a drop of methyl cellulose. The ground electrode was clamped onto the tail. To maintain body temperature at $37^{\circ} \mathrm{C}$, the mouse rested on homeothermic blanket connected to a control unit (Harvard Apparatus). The light stimulus was delivered from a desk-top ganzfeld stimulator (Color Dome, Diagnosys LLC, Littleton, MA) and responses were recorded on the Espion console. LED output wavelengths were measured with a CCD-spectrometer (Ocean Optics Inc., Dunedin, FL). Recordings lasted about $20 \mathrm{~min}$, blue or amber LED flashes (5-flashes) preceded red flashes (17-flashes; Xenon lamp with $<640 \mathrm{~nm}$ cut off filter) and a 20-30 s adaptation time was allowed between flashes. Recordings were repeated in each mouse up to three times.

\section{Results}

For our studies we selected the water-soluble chlorophyll derivative chlorin $e_{6}$ (Scheme 1), which is used as a food colorant, a dietary supplement ${ }^{22}$ and in cancer therapy. ${ }^{23}$ Commercially, chlorins are prepared from acid or base treatment and/or transmetalation of chlorophyll $a$ according to Scheme $1 .^{24-26}$

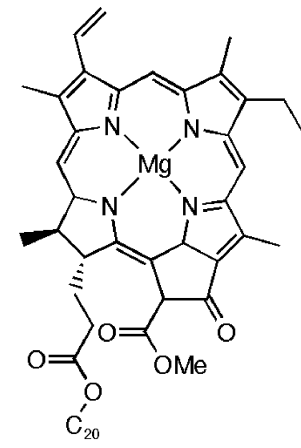

Chlorophyll

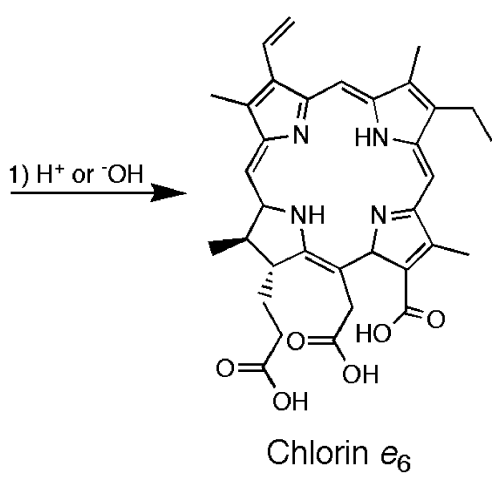

Scheme 1
In order to determine whether the water-soluble chlorophyll derivative chlorin $e_{6}$ could penetrate the mouse blood-retina barrier and localize in mammalian photoreceptor cells that contain the visual pigments, mice $(n=4)$ were intravenously injected with a solution of chlorin $e_{6}$. One hour after administration the eyes were removed and fluorescence spectroscopy was performed on a chloroform : $\mathrm{MeOH}(3: 1)$ extract of the posterior eyecup tissue, the results of which are shown in Fig. 1. Along with a weak emission band centered at $450 \mathrm{~nm}$, which was assigned to native eye pigments, ${ }^{27}$ a strong emission band centered at $675 \mathrm{~nm}$ was

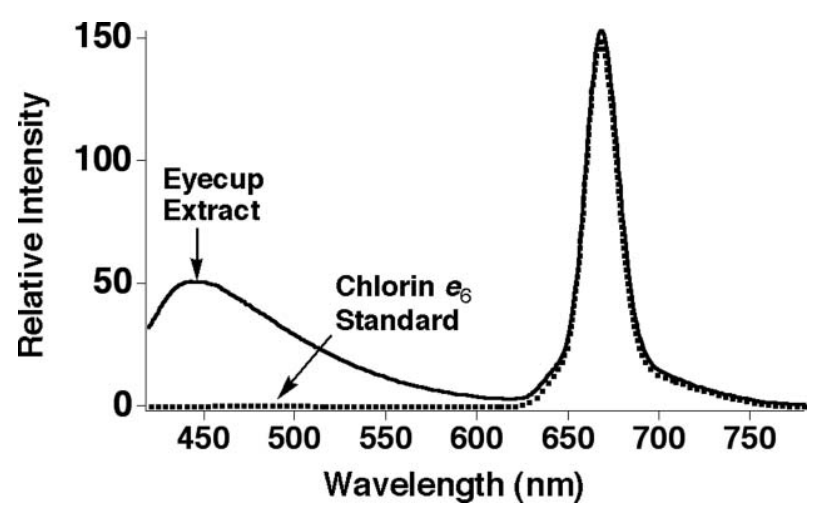

Fig. 1 Solid line: fluorescence spectrum of a chloroform : $\mathrm{MeOH}(3: 1)$ extract of eyecups dissected form mice $(n=4) 1 \mathrm{~h}$ after i.v. administration of chlorin $e_{6}\left(2 \mathrm{mg} \mathrm{kg}^{-1}\right) ; 400 \mathrm{~nm}$ excitation. Dotted line: fluorescence spectrum of a chloroform: $\mathrm{MeOH}(3: 1)$ solution of chlorin $e_{6} ; 400 \mathrm{~nm}$ excitation. 
observed. This $675 \mathrm{~nm}$ band was assigned to chlorin $e_{6}$, since in a standard solution of chlorin $e_{6}$ prepared in the same solvent, (Fig. 1; dotted line) a strong fluorescence band centered at $675 \mathrm{~nm}$ was also observed. This $675 \mathrm{~nm}$ band was not observed in eyecup extracts of non-injected mice (data not shown).

A second group of mice $(n=3)$ was administered chlorin $e_{6}$. One, two and three hours after injection the eyes were dissected and the whole retinas mounted and viewed under a fluorescence microscope. At all three times, red fluorescence $(>640 \mathrm{~nm})$ was observed in the retinas of injected mice (data not shown) but not in retinas of control mice. These observations indicated that intravenously injected chlorin reaches the retina and remains three hours post administration. These observations are in accord with similar experiments in rabbit models. ${ }^{28}$

In order to determine whether the red fluorescence was localized within the retina, a third group of mice $(n=2)$ was administered chlorin $e_{6}$. One and two hours after injection, the eyes were enucleated, cross-sectioned and viewed under a fluorescence microscope. Fig. 2A shows a microscopic image of a cross section of a retina. The pigment epithelium (PE) and outer segment layer (OS), inner segment (IS), outer nuclear layer (ONL) and the ganglion cell layer (GCL) are labeled. Fig. 2B shows the same cross section under fluorescence conditions (ext. $400 \mathrm{~nm}$ band pass filter; em. $<640 \mathrm{mn}$ cut off filter). Red fluorescence was localized in the outer and inner segment layers and the pigment epithelium layer. Very little red fluorescence was found in the other layers of the retina, such as the ONL and GCL layers. This suggests preferential accumulation of chlorin near the visual pigments.

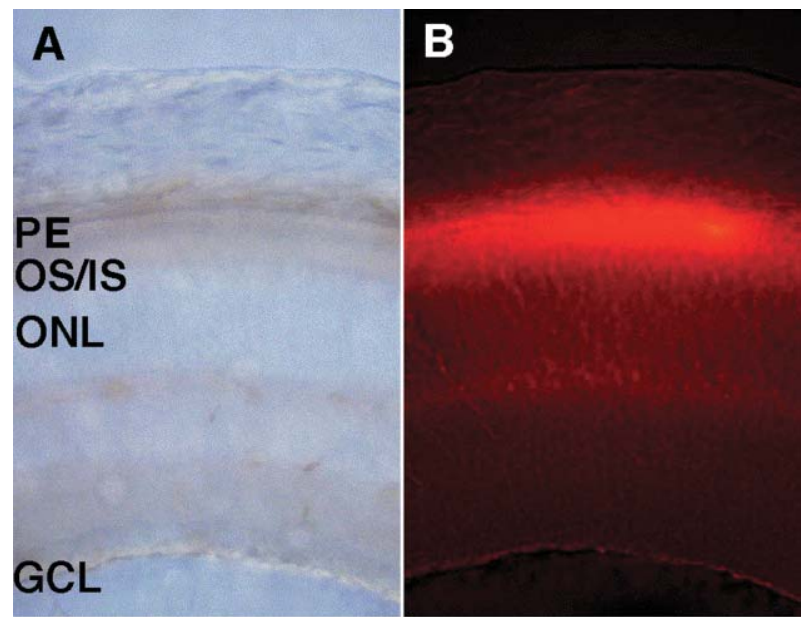

Fig. 2 Microscope images of a cross section of a retina dissected from a mouse $1 \mathrm{~h}$ after i.v. administration of chlorin $e_{6}\left(2 \mathrm{mg} \mathrm{kg}^{-1}\right)$. (A) PE: pigment epithelium, OS: outer segment layer, IS: inner segment layer, ONL: outer nuclear layer, GCL: ganglion cell layer. (B) Under fluorescence conditions (ext. $400 \mathrm{~nm}$ band pass filter; em. $<650 \mathrm{~nm}$ cut off filter) accumulation of red fluorescence is seen.

The retinal response to red (>640 nm) light was subsequently measured by ERG recordings. Typical ERG curves are shown in Fig. 3. For both injected and control mice, at low red light stimulus the ERG showed a slow and positive b-wave. As the light intensity increased, the b-wave increased in amplitude. With yet brighter stimuli, the negative a-wave appeared. With further increase in the flash intensity, both the a-wave and the b-wave increased in

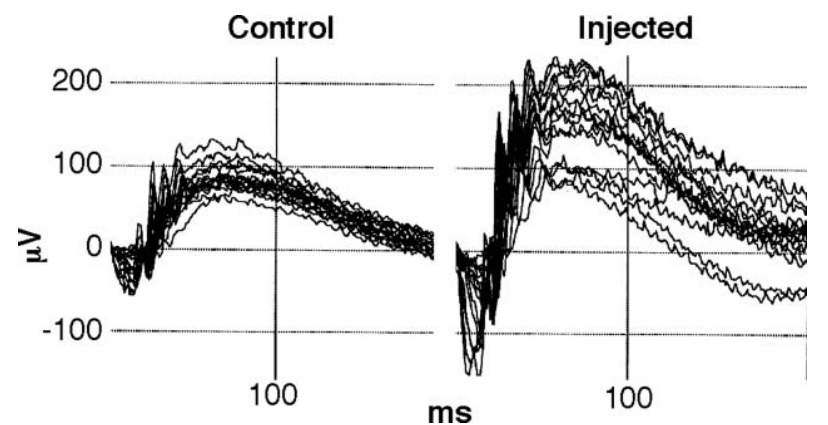

Fig. 3 Typical ERG curves for mice exposed to red $(<650 \mathrm{~nm}$ cut off filter) light for a control, left plot, and a chlorin $e_{6}$ administered, right plot, mouse for light intensities spanning 1.3-2.85 relative log units.

amplitude and oscillatory potentials were seen on the rising phase of the b-wave.

Fig. 4 shows mean b-wave amplitudes generated in response to a single red light stimulus for injected and non-injected mice. Chlorin administered mice showed an almost two-fold increase in b-wave amplitude when compared to control mice. Similar plots where obtained for fourteen other red light stimuli with light intensities spanning 1.3-2.85 relative log units. For all intensities studied, the chlorin administered mice showed an almost two-fold increase in b-wave amplitudes.

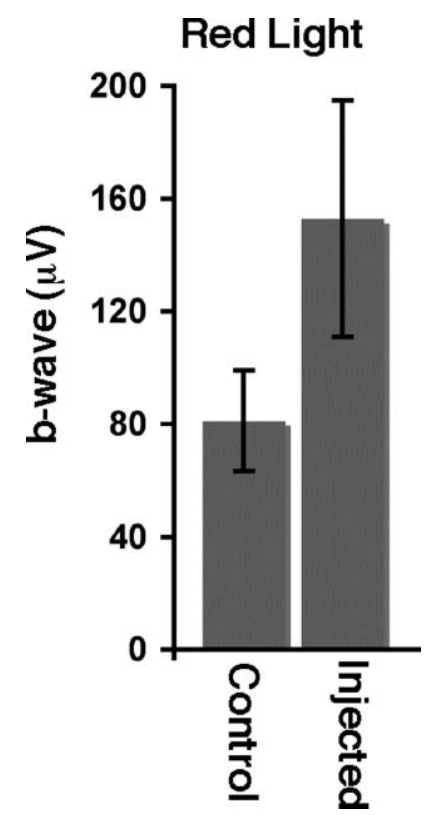

Fig. 4 ERG-b wave amplitudes (Ganzfeld ERG equipped with a $<640 \mathrm{~nm}$ cut off filter) in response to a single flash of red light for control mice $(n=7)$ and mice administered chlorin $e_{6}(n=10)$. Data are presented as mean \pm standard deviation. The difference in b-wave amplitudes was statistically significant for control and injected mice. Student's $t$-test: $p=$ 0.0001 .

Chlorin $e_{6}$ strongly absorbs light centered at both 400 and $665 \mathrm{~nm}$, corresponding to the Soret and Q-bands, respectively. Thus in addition to red light $(>640 \mathrm{~nm})$, the retinal response to blue light $\left(456 \mathrm{~nm} \pm 30 \mathrm{~nm} ; 0.01 \mathrm{~cd} \mathrm{~s} \mathrm{~m}^{-2}\right)$ was measured for injected and non-injected mice. As shown in Fig. 5, the injected mice $(n=10)$ exhibited an almost two-fold increase 


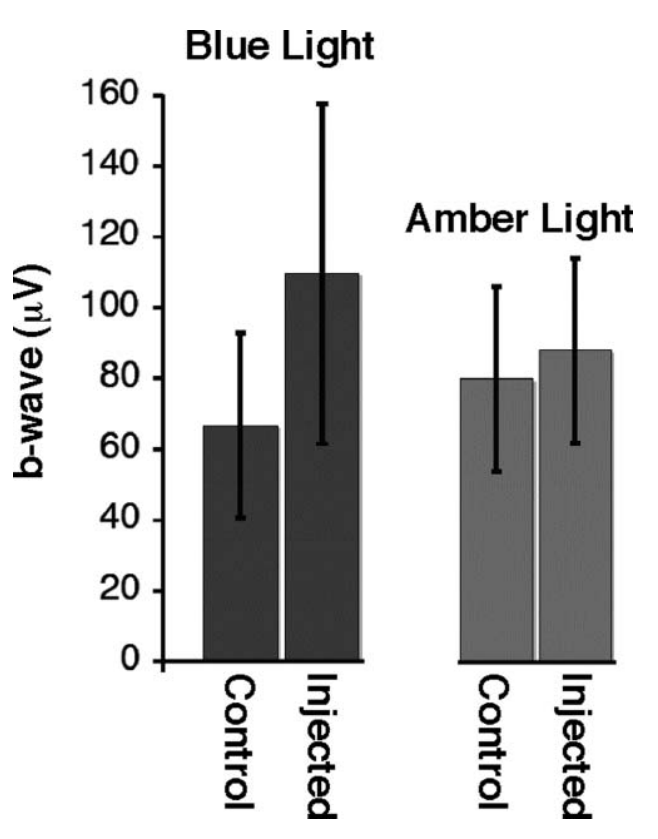

Fig. 5 ERG b-wave amplitudes plotted against blue $(456 \pm 30 \mathrm{~nm})$ and amber $(589 \pm 20 \mathrm{~nm})$ LED flashes at $\left(0.01 \mathrm{~cd} \mathrm{~s} \mathrm{~m}^{-2}\right)$ for control (blue: $n=$ 10; amber: $n=4$ ) and chlorin injected (blue: $n=10$ : amber: $n=4)$ mice. Data are presented as mean \pm standard deviation.

in b-wave amplitudes as compared to control mice in response to blue light, although more scatter was observed compared to responses elicited from the red light flashes. On the other hand, the absorbance of chlorin $e_{6}$ to amber centered light, $589 \pm 20 \mathrm{~nm}$, is minimal; no increase in retinal activity to amber light $(0.01 \mathrm{~cd} \mathrm{~s}$ $\mathrm{m}^{-2}$ ) was observed by ERG measurements in chlorin-administered mice $(n=4)$, as shown in Fig. 5 .

\section{Discussion}

We observe that mice intravenously injected with a solution of $2 \mathrm{mg} \mathrm{kg}^{-1}$ of chlorin $e_{6}$ preferentially accumulate the chromophore in the retina outer segment. It has been observed that humans given chlorin supplements (12 $\mathrm{mg} \mathrm{d}^{-1}$; orally) accumulate steadystate plasma concentrations of up to $2 \mathrm{mg} \mathrm{ml}^{-1} .{ }^{29}$ The similar chlorophyll derivative, phylloerythrin, has been detected in the blood $^{30}$ and urine ${ }^{31,32}$ in many mammals including humans on vegetable diets.

The photoreceptor cells of the mouse retina are predominantly $(98 \%)$ rods and thus maximally absorb in the blue-green region of the spectrum $(500 \mathrm{~nm}) .{ }^{33}$ The remaining cone cells have peak sensitivities at 360 (UV-pigment) and 509-512 nm (M-pigment). ${ }^{34}$ Following protocols widely used in clinical and experimental analysis of retinal function, we plotted b-wave amplitudes generated in response to red, blue and amber light for chlorin $e_{6^{-}}$ injected and non-injected mice. The b-wave arises largely from the polarization of bipolar cells and can be used as a downstream measure of photoreceptor function. In the presence of chlorin an almost two-fold increase in neural impulse was generated in the retina in response to red and blue light, but not amber light. The stimulus wavelengths generating the increased visual response correspond to the absorption spectrum of chlorin $e_{6}$. Since systemically injected chlorin was also localized to retina, we conclude that the increase in visual sensitivity is a result of light absorption by chlorin.

In summary, the above data along with our past research shows that derivatives of chlorophyll can act as visual pigments initiating the transformation of light into an electrical signal. In doing so the primary event in vision is changed from initial activation of the protein opsin to initial activation of a chlorophyll derivative. This mechanism is shown to enhance vision in a mouse model and perhaps could also do so in humans.

\section{Acknowledgements}

This work was supported by the National Institute of Health (I.W. NRSA EY T32 013933; J.R.S. EY12951; K.N. GM036564 and the National Science Foundation (N.J.T. CHE-04-1516).

\section{References}

1 For a recent review on rhodopsin see: N. Fishkin, K. Nakanishi and N. Berova, Primary events in dim light vision: a chemical and spectroscopic approach toward understanding protein/chromophore interactions in rhodopsin, Chem. Rec., 2004, 4, 120.

2 S. Johnsen, The red and the black: Bioluminescence and the color of animals in the deep sea, Integr. Comp. Biol., 2005, 45, 234-246.

$3 \mathrm{~W}$. S. Stiles, The scattering theory of the effect of glare on the brightness difference threshold, Proc. R. Soc. London, Ser. B, 1929, 105, 131-141.

4 V. Kefalov, Y. Fu, N. Marsh-Armstrong and K. W. Yau, Role of visual pigment properties in rod and cone phototransduction, Nature, 2003, 425, 526-31.

5 V. J. Kefalov, M. E. Estevez, M. Kono, P. W. Goletz, R. K. Crouch, M. C. Cornwall and K.-W. Yau, Breaking the covalent bond: A pigment property that contributes to desensitization in cones, Neuron, 2005, 46, 879-890.

6 K. Kirschfeld, N. Franceschini and B. Minke, Evidence for a sensitizing pigment in fly photoreceptors, Nature, 1977, 269, 386-390.

$7 \mathrm{~K}$. Kirschfeld and K. Vogt, Does retinol serve a sensitizing function in insect photoreceptors?, Vision Res., 1986, 26, 1771-1777.

8 S. P. Balashov, E. S. Imasheva, V. A. Boichenko, J. Antón, J. M. Wang and J. K. Lanyi, Xanthorhodopsin: A proton pump with a lightharvesting carotenoid antenna, Science, 2005, 309, 2061-2064.

9 J. K. Bowmaker, H. J. A. Dartnall and P. J. Herring, Longwavesensitive visual pigments in some deep-sea fishes: segregation of 'paired' rhodopsins and porphyropsins, J. Comp. Physiol. A, 1988, 163, 685698.

10 R. H. Douglas, J. C. Partridge, J. C., K. Dulai, D. Hunt, C. W. Mullineaux, A. Y. Tauber and P. H. Hynninen, Dragon fish see using chlorophyll, Nature, 1998, 393, 423.

11 I. Washington, C. Brooks, N. J. Turro and K. Nakanishi, Porphyrins as photosensitizers to enhance night vision, J. Am. Chem. Soc., 2004, 126, 9892-9893.

12 T. Isayama, D. Alexeev, C. L. Makino, I. Washington, K. Nakanishi and N. J. Turro, An accessory chromophore in red vision, Nature, 2006, 443,649 .

13 S. H. D. Haddock, C. W. Dunn, P. R. Pugh and C. E. Schnitzler, Bioluminescent and red-fluorescent lures in a deep-sea siphonophore, Science, 2005, 309, 263.

14 J. S. Levine and E. F. MacNichol, Color vision in fishes, Scient. Am., 1982, 246, 140-149.

15 R. H. Douglas, J. C. Partridge and N. J. Marshall, The eyes of deep sea fish I. Lens pigmentation, tapeta and visual pigments, Prog. Retin Eye Res., 1998, 17, 597-636.

16 E. J. Warrant and N. A. Locket, Vision in the deep sea, Biol. Rev., 2004, 79, 671-712.

17 R. W. Robey, K. Steadman, O. Polgar and S. E. Bates, ABCG2meadiated transport of photosensitizers-potential on photodynamic therapy, Cancer Biol. Therapy, 2005, 4, 187-194.

18 I. Izumi, S. B. Hammerman, A. N. Benz, J. Labruyere, C. F. Zorumski and J. W. Olney, Comparison of rat retinal fixation techniques: Chemical fixation and microwave irradiation, Exp. Eye Res., 2000, 70, 191-198. 
19 S. M. Saszik, J. G. Robson and L. T. Frishman, The scotopic threshold response of the dark-adapted electroretinogram of the mouse, J. Physiol., 2002, 543, 899-916.

20 N. S. Peachey and S. L. Ball, Electrophysiological analysis of visual function in mutant mice, Doc. Ophthalmol., 2003, 107, 13-36.

21 L. H. Pinto, M. H. Vitaterna, S. M. Siepka, K. Shimomura, S. Lumayag, M. Baker, D. Fenner, R. F. Mullins, V. C. Sheffield, E. M. Stone, E. Heffron and J. S. Takahashi, Initial results from screening over 9000 chemically-mutagenized mice for defects in the electroretinogram and appearance of the fundus, Vision Res., 2004, 44, 33353345.

22 PDR for Nutritional Supplements, in Chlorophyll/Chlorophyllin, ed. S. S. Hendler and D. Rorvick, Medical Economics Company, Montvale, NJ, 2001, pp. 88-90.

23 N. Lane, New light on medicine, Scient. Am., 2003, 288, 38-45.

24 J. C. Kephart, Chlorophyll derivatives - their chemistry, commercial preparation and uses, Econ. Bot., 1955, 9, 3-38.

25 M. Sato, I. Fujimoto, S. Toshimori, A. Tachio, K. Ryohei and T. Murata, Effect of sodium copper chlorophyllin on lipid peroxidation IX. On the antioxidant components in commercial preparations of sodium copper chlorophyllin, Chem. Pharm. Bull., 1986, 34, 24282434.

26 H. Inoue, H. Yamashita, K. Furuya, Y. Nonomura, N. Yashioka and $\mathrm{S}$. Li, Chlorophyllin by reversed-phase high-performance liquid chromatography, J. Chromatogr., 1994, 679A, 99-104.
27 N. E. Fishkin, J. R. Sparrow, R. Allikmets and K. Nakanishi, Isolation and characterization of a retinal pigment epithelial cell fluorophore: An all-trans-retinal dimer conjugate, Proc. Natl. Acad. Sci. USA, 2005, 102, 7091-796.

28 R. Haimovici, T. A. Ciulla, J. W. Miller, T. Hasan, T. J. Flotte, A. G. Kenney, K. T. Schomacker and E. S. Gragoudas, Localization of rose bengal, aluminum phthalocyanine tetrasulfonate, and chlorin $e_{6}$ in the rabbit eye, Retina-J. Ret. Vit. Dis., 2002, 22, 65-74.

29 P. A. Egner, K. H. Stansbury, E. P. Snyder, M. E. Rogers, P. A. Hintz and T. W. Kensler, Identification and characterization of chlorin e(4) ethyl ester in sera of individuals participating in the chlorophyllin chemoprevention trial, Chem. Rev. Toxicol., 2000, 13, 900-906.

30 D. D. Perrin, The determination of phylloerythrin in blood, Biochem. J., 1958, 2, 314-318.

31 D. Kemeri, A new porphorin component in normal human faeces, Biochem. Z., 1924, 151, 446.

$32 \mathrm{H}$. Fischer and H. Hilmer, Information on phylloerythrin. II. Remarks on the treatise of Mr. Dr Kemeris "A new porphyrin like constituent of normal human skin", Z. Physiol. Chem., 1925, 143, 1-8.

33 L. D. Carter-Dawson and M. M. La Vail, Rods and cones in the mouse retina. II. Autoradiographic analysis of cell generation using tritiated thymidine, J. Comp. Neur., 1979, 188, 263-272.

34 G. H. Jocobs, G. A. Williams and J. A. Fenwick, Influence of cone pigment coexpression on spectral sensitivity and color vision in the mouse, Vision Res., 2004, 44, 1615-162. 